\title{
PERANCANGAN VIDEO MOTION GRAPHIC SEBAGAI MEDIA EDUKASI TENTANG CYBER CRIME
}

\author{
Dwi Agnes Natalia Bangun \\ Politeknik Negeri Jakarta
}

\begin{abstract}
Aktivitas cyber crime di Indonesia mengalami peningkatan setiap tahun. Tercatat 3.429 kasus cyber crime dari Januari hingga Agustus 2019. Bahkan, Indonesa merupakan negara dengan kejahatan cyber crime terbesar kedua di dunia pada tahun 2018. Salah satu penyebab isu kontemporer ini adalah karena rendahnya kesadaran masyarakat dalam kesiapsiagaan terhadap cyber crime. Sebagai salah satu upaya pencegahan aktivitas cyber crime, dirancang video motion graphic sebagai media edukasi. Metode penelitian menggunakan pendekatan kualitatif dengan teknik pengumpulan data in-depth interview, studi literatur dan dokumentasi. Perancangan video ini dilakukan dengan tahapan proses kreatif yaitu idea development, concept visualization, evaluation, dan final artwork. Hasil perancangan ini yaitu berupa video motion graphic berdurasi 6 menit 35 detik dengan konsep desain modern dan minimalis yang divisualisasikan melalui open composition dan assymetrical layout, flat dan outline vector illustration, vivid duo-tone color, dan maxi typography, serta konsep komunikasi storytelling yang santai, sederhana, dan to-the-point. Perancangan video motion graphic ini menjadi media informasi mengenai contoh-contoh tindakan cyber crime yang disadari maupun tidak disadari serta dampaknya yang berupa sanksi hukum yang diatur dalam UU ITE No. 19 Tahun 2016. Melalui video ini, wawasan masyarakat tentang cyber crime dapat bertambah dan membantu masyarakat untuk lebih waspada dalam menggunakan jarinya di media sosial.
\end{abstract}

Kata Kunci: Desain Grafis, Motion Grafis, Cyber Crime

\begin{abstract}
Cyber crime activity in Indonesia has increased every year. There are 3,429 cases of cyber crime from January to August 2019. In fact, Indonesia is the country ranks second for the largest cyber crime in the world in 2018. One of the causes of this contemporary issue is due to low public awareness in preparedness against cyber crime. As one of the efforts to prevent cyber crime activities, motion graphic video is designed as an educational media. The research method uses a qualitative approach with data collection techniques in-depth interviews, literature studies and documentation. The design of this video is done through the stages of the creative process namely idea development, concept visualization, evaluation, and final artwork. The results of this design are 6 minute 35 second motion graphic video with modern and minimalist design concepts visualized through open composition and assymetrical layout, flat and outline vector illustrations, vivid duo-tone colors, and maxi typography, and relaxed storytelling communication concepts. , simple, and to-the-point. The design of this motion graphic video becomes a media of information regarding examples of cyber crime that are realized or not as well as their impact in the form of legal penalty regulated in Indonesia ITE Law (UU ITE No. 19 Tahun 2016). Through this video, people's insights about cyber crime can increase and help the public to be more vigilant in using social media.
\end{abstract}

Keywords: Graphic Design, Motion Graphic, Cyber Crime

Correspondence author: Dwi Agnes Natalia Bangun, dwi.agnes@grafika.pnj.ac.id, Depok, Indonesia 


\section{Pendahuluan}

Cyber crime adalah semua tindakan kejahatan yang terjadi dan beroperasi di dunia maya dengan menggunakan komputer, jaringan komputer dan internet. Tindakan cyber crime dibedakan menjadi empat tipe pelanggaran (Gercke 12), yaitu :

1. Pelanggaran terkait data dan sistem komputer, mencakup akses ilegal, akuisisi data ilegal, penyadapan ilegal, intervensi data, dan intervensi sistem

2. Pelanggaran terkait konten, mencakup pornografi, hate speech, cyberbulliying, hoax, spam, dan konten ilegal.

3. Pelanggaran terkait komputer, mencakup penipuan di dunia maya, pemalsuan data, pencurian identitas

4. Pelanggaran terkait hak cipta dan trademark, mencakup pelanggaran hak cipta dan pelanggaran merek

Dalam bidang teknologi informasi, tipe pelanggaran yang marak terjadi yaitu pelanggaran terkait konten. Ada bentuk tindakan pelanggaran terkait konten yang mengarah kepada kekerasan, dalam hal ini yaitu kekerasan di dunia maya, seperti cyberbulliying. Jenis-jenis cyberbulliying yang perlu dikenali, yaitu flaming, denigration, impersonation, harassment, outing, exclusion, dan cyberstalking (Eriviany 1). Selain cyberbulliying, tindak kejahatan di dunia maya yang terkait konten yaitu pornografi, hate speech, dan hoax.

Tindakan pelanggaran terkait konten merupakan tindakan yang tidak disadari oleh para pelakunya, umumnya dilakukan pada media sosial. Usia pengguna media sosial terbanyak tahun 2019 yaitu usia 18 - 34 tahun. Umumnya, mereka adalah masyarakat yang paham teknologi (tech-savvy). Tindakan pelanggaran terkait konten yang dilakukan generasi milenial ini disebabkan karena penggunaan media sosial yang tidak bijaksana dan karena minimnya wawasan mereka tentang cyber crime.

Hasil data riset awal menunjukkan bahwa kesadaran masyarakat dalam kesiapsiagaan terhadap isu kontemporer cyber crime di media sosial masih rendah. Hal ini ditunjukkan melalui hasil data riset yang dilakukan terhadap 111 responden mahasiswa di Jurusan Teknik Grafika Penerbitan Politeknik Negeri Jakarta (PNJ). Data menunjukkan 9,9\% mahasiswa (11 orang) menyatakan pernah melakukan cyber crime dan 31,5\% (35 orang) menyatakan mungkin pernah melakukan tindakan cyber crime. Sebanyak 50,9\% mahasiswa (55 orang) menyatakan pernah menjadi korban cyber crime di media sosial. Sebanyak $45 \%$ mahasiswa (50 orang) menyatakan beberapa kali melihat/menemukan cyber crime di media sosial. Sebanyak 59,1\% mahasiswa (65 orang) menyatakan tidak tahu mengenai UU Nomor 19 Tahun 2016 tentang Informasi Dan Transaksi Elektronik. Dari hasil data yang terkumpul, dapat ditarik kesimpulan bahwa belum semua mahasiswa memahami tindakan cyber crime yang dilakukan dan tindak pidana yang harus dihadapi ketika melakukan kejahatan dalam komunikasi media sosial, dalam hal ini yaitu cyber crime.

Penggunaan media sosial yang sangat masif di tengah generasi milenial tidak mungkin bisa diawasi oleh tenaga pendidik, dalam hal ini para dosen, bahkan dosen pembimbing akademik sekalipun. Hal ini menyebabkan potensi kejahatan komunikasi media sosial tidak bisa terdeteksi dan dicegah. Isu ini menjadi prioritas karena dianggap serius dan memiliki perkembangan masalah yang tinggi jika tidak segera diatasi. Karakter diri yang tidak professional, khususnya dalam hal berkomunikasi pada media media sosial dapat menjadikan kualitas lulusan kurang bermutu, terlebih jika ada penemuan jejak digital yang menunjukkan adanya indikasi kejahatan komunikasi media sosial. Reputasi lulusan terbentuk dari kepribadian 
yang dibangun selama menjadi mahasiswa. Ketika reputasi tersebut jatuh, dan jatuh pulalah reputasi institusi.

Strategi pemecahan masalah yang dilakukan sebagai salah satu solusi untuk menangani masalah ini yaitu melalui pembuatan video tentang bahaya cyber crime. Gagasan ini dipilih sebagai solusi karena secara media, sosialisasinya lebih efektif dapat disebarkan melalui media sosial, dari segi waktu efisien karena target hanya perlu menonton tayangan, dan secara penggunaan sangat mudah karena setiap mahasiswa dapat melihatnya di media sosial (Youtube, dan lainnya). Selain daripada itu, paparan informasinya bisa jauh lebih luas, tidak hanya mahasiswa PNJ saja, namun juga seluruh mahasiswa di Indonesia.

Berdasarkan paparan di atas, maka rumusan masalah dalam perancangan video motion graphic ini adalah bagaimana merancang video motion graphic yang dapat mengedukasi mahasiswa mengenai cyber crime. Perancangan video motion graphic ini mencakup bagaimana menyusun konsep komunikasi dan visual dalam membuat konten video.

\section{Metode}

Penelitian ini menggunakan pendekatan kualitatif dengan teknik pengumpulan data yaitu melalui :

1. In-depth interview dengan Bapak Dwi Sujarwanto, perwakilan Subdit Cyber Reskrimsus Polda Metro Jaya untuk mendapatkan data tentang tindakan kejahatan, penggunaan UU ITE No. 19 Tahun 2016 dalam menangani kasus cyber crim, dan alur proses penanganan cyber crime di Indonesia.

2. Studi literatur mengenai kasus-kasus cyber crime dan UU ITE No. 19 Tahun 2016 sebagai bahan untuk menyusun storytelling dan konten video.

3. Dokumentasi video mengenai cyber crime yang sudah ada di Youtube untuk menghindari plagiarisme juga sebagai referensi video.

Data dan fakta terkait objek penelitian dari in-depth interview, studi literatur, dan dokumentasi diriset dan dianalisis. Hasil analisa data digunakan untuk mendapatkan konsep visual, komunikasi, dan konten untuk menyusun storyline dan visual dalam proses perancangan video motion graphic.

Konsep awal yang muncul berdasarkan hasil analisa data yaitu membuat video motion graphic dengan beberapa video klip pendek, yaitu mengangkat tentang isu anonimitas pada tindakan, penyebaran hoax karena kurangnya referensi, penyebaran video pornografi, dan penjelasan menyeluruh mengenai cyber crime. Ketiga isu ini diangkat karena memiliki hubungan dengan kebiasaan dan gaya hidup target, juga untuk menyentuh sisi moral mereka.

Tahap berikutnya yaitu proses kreatif pada perancangan video motion graphic. Proses kreatif ini adalah sebagai berikut :

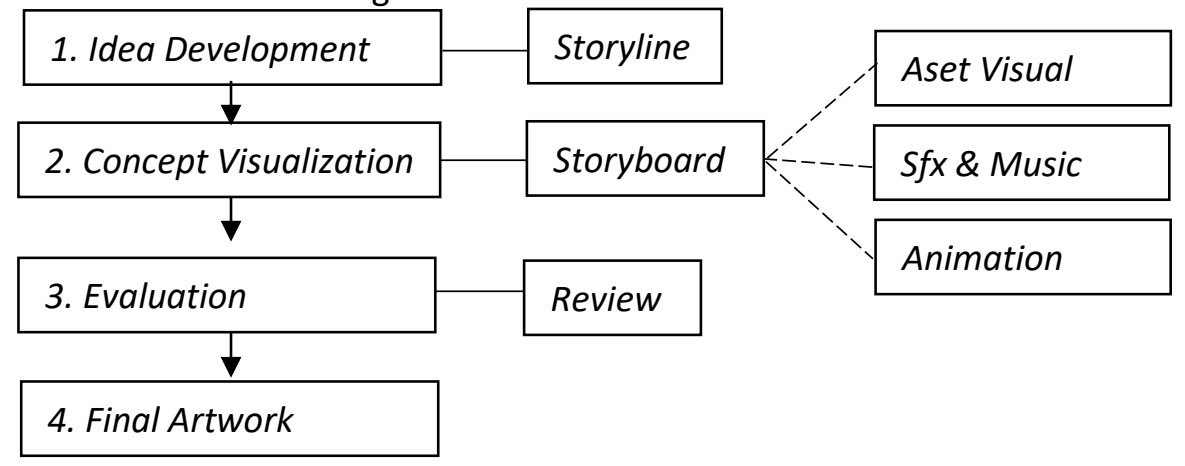

Gambar 1 Proses Kreatif 
1. Idea Development

Tahap awal dalam proses kreatif adalah idea development (pengembangan ide). Dalam proses pengembangan ide ini, langkah yang dilakukan adalah menganalisa hasil data yang telah dikumpulkan dan menyusun konsep berdasarkan hasil analisa data. Pada penelitian awal yang menggunakan kuesioner, hasil menunjukkan bahwa mahasiswa belum memahami tindakan cyber crime dan tindak pidana yang harus dihadapi ketika melakukan kejahatan dalam komunikasi media sosial. Poin ini menjadi dasar pemikiran tujuan pembuatan video, yaitu menyadarkan target audiens bahwa aktifitas negatif yang dilakukan baik dengan sadar maupun tidak sadar memiliki dampak yang berkaitan dengan sanksi hukum yang diatur UU ITE.

Pada tahap pengembangan konsep, hal-hal yang menjadi pertimbangan adalah pemilihan konten yang mencakup apa saja informasi yang akan disampaikan, segmentasi target untuk menentukan konsep komunikasi, juga bagaimana pesan akan dikemas dan disampaikan kepada target audiens. Proses penyusunan konsep ini dilakukan dengan berdiskusi dengan narasumber dan pakar terkait.

Output pada tahap pengembangan ide ini adalah storyline yang berisi mengenai alur animasi dan script yang akan digunakan untuk voice over. Storyline (ide cerita) yang dibuat mencakup beberapa tindakan cyber crime yang umum dan sering kali tidak disadari sebagai tindakan cyber crime yaitu anonimitas, penyebaran hoax, pornografi, dan penjelasan UU ITE dan lingkup tindakan cyber crime.

\section{Concept Visualization}

Setelah mendapatkan konsep alur cerita dalam bentuk storyline, tahap selanjutnya adalah concept visualization (visualisasi konsep). Visualisasi konsep dilakukan mengacu pada storyline yang telah dibuat. Dari storyline dibuat sketsa storyboard untuk melihat tampilan alur animasi dalam bentuk visual. Setelah storyboard selesai dibuat, langkah selanjutnya yaitu menentukan kebutuhan aset visual yang kemudian dibuat dalam bentuk digital, pencarian musik dan efek suara yang relevan, dan dilanjutkan dengan proses animasi.

Konsep visual dilakukan dengan mempertimbangkan segmentasi target audiens, jenis informasi pesan yang akan disampaikan. Pada tahap visualisasi konsep, baik pada proses storyboard maupun layout digital dilakukan dengan menerapkan elemen dan prinsip desain grafis, sementara pada proses animasi dilakukan dengan menerapkan prinsip motion graphic

\section{Evaluation}

Evaluasi dilakukan setelah video dapat dipreview. Tahap ini dilakukan untuk melihat kesesuaian durasi, timing antar efek visual dan suara, dan movement. Tahap ini dapat dilakukan berulang kali hingga mendapatkan tampilan video yang nyaman dipandang. Evaluasi juga dilakukan terhadap konten video, termasuk pengecekan kesalahan pengetikan konten, pencantuman sumber data dan kredit.

\section{Final Artwork}

Final artwork video merupakan hasil akhir video motion graphic yang siap untuk dipublish dan ditayangkan. 


\section{Hasil dan Pembahasan}

Video motion graphic ini diberi judul "Jaga Jari dari Cyber Crime". Dalam hal komunikasi di media sosial, jari memiliki peran penting. Ketika otak telah mengingat fitur pada media sosial, maka jari dengan mudah bergerak dan melakukan aktivitas di media sosial bahkan dengan mata tertutup sekalipun. Ketika jari digunakan tanpa pemikiran yang panjang dan matang, maka seringkali jari kemudian "kebablasan" melakukan hal yang tidak seharusnya, dalam hal ini yaitu pelanggaran cyber crime terkait konten. Judul "Jaga Jari dari Cyber crime" dibuat untuk memberi sugesti kepada audiens untuk menjaga jarinya dari segala tindakan cyber crime. "Jaga Jari" juga menjadi tagline untuk video karena sederhama, terdengar singkat dan mudah diingat.

Target audiens video motion graphic ini yaitu dikhususnya untuk pelajar dan mahasiswa dengan segmentasi target sebagai berikut :

1. Demografi : Mahasiswa, Laki-laki dan perempuan, 18 - 25 tahun, SES B, tinggal di Jabodetabek

2. Psikografis : kekinian, cenderung apatis di dunia nyata, kurang punya rasa empati, suka hal yang instan dan cepat, mudah bosan.

3. Behavioural Profile : aktif dan eksis di media sosial, update berita populer, paham teknologi digital, pengguna aktif internet

Profil target audiens ini menjadi bahan pertimbangan dalam menentukan konsep alur cerita, konsep visual dan komunikasi dalam video motion graphic.

Durasi video motion graphic ini yaitu 6 menit 35 detik dengan resolusi $1280 \times 720$ px dan format video MP4. Waktu 6 menit 35 detik ini dibagi menjadi empat klip, yaitu :

1. Cyberbulliying, berisi contoh kasus cyberbulliying di Instagram, proses pelacakan akun anonim, jenis-jenis cyberbuliying, dan sanksi hukum terhadap cyberbulliying yang diatur dalam UU ITE No. 19 Tahun 2016 pasal 45 ayat 3

2. Hoax, berisi contoh kasus penyebaran hoax, penanganan terhadap pelaku penyebar hoax, sanksi hukum terhadap hoax yang diatur dalam UU ITE No. 19 Tahun 2016 pasal 45A ayat 1 , dan himbauan untuk mengecek validitas berita sebelum menyebarkan ke orang lain.

3. Pornografi, berisi contoh kasus penyebaran video porno, penangkapan dan peradilan, dan sanksi hukum terhadap penyebaran pornografi yang diatur dalam UU ITE No. 19 Tahun 2016 pasal 45 ayat 1.

4. Penjelasan cyber crime, berisi mengenai definisi cyber crime, tipe-tipe pelanggaran cyber crime, cyber patrol, dan tagline.

Pada klip pertama sampai dengan ketiga, yaitu pada klip contoh kasus cyber crime, alur cerita dibuat dengan pola yang serupa yaitu :

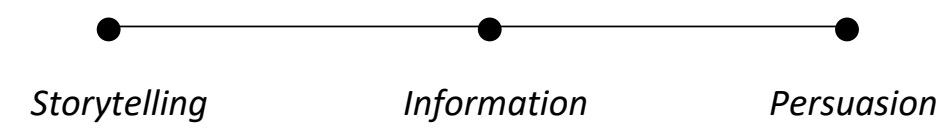

Gambar 2 Pola Alur Cerita

Konsep pola alur cerita ini adalah untuk membangun minat audiens untuk menonton video melalui storytelling yang ringan dan pendek, memberi wawasan berupa informasi setelah audiens memiliki rasa penasaran, dan mengakhirinya dengan persuasi yaitu himbauan untuk menghindari tindak kejahatan cyber crime. 
Video ini diunggah di channel Youtube (Link : bit.ly/jaga-jari) sejak tanggal 30 Maret 2019. Video ini selain diunggah di Youtube juga dibagikan di media sosial lain seperti Facebook, Instagram, dan grup-grup Whatsap. Selain itu, video ini juga digunakan sebagai materi perkuliahan di mata kuliah Kewarganegaraan. Sampai pada tanggal 14 November 2019 telah ditonton sebanyak 977 kali.

\section{Storyline}

Konsep cerita video ini adalah dengan menyajikan short storytelling yang menampilkan beberapa contoh kasus cyber crime dalam kehidupan sehari-hari di kalangan mahasiswa. Tiga contoh kasus yang diangkat dalam video yaitu cyberbulliying, hoax, dan pornografi. Flow storyline memiliki pola alur cerita yaitu contoh kasus yang dikemas dalam bentuk cerita pendek, penjelasan UU ITE tentang sanksi tindak kejahatan terkait, dan diakhiri dengan saran/nasihat.

Tabel 1 Storyline Video

\begin{tabular}{|c|c|c|}
\hline PART & SCRIPT & KETERANGAN ANIMASI \\
\hline $\begin{array}{l}\text { Klip } 1 . \\
\text { Cyberbulliying } \\
\text { dengan Akun } \\
\text { Anonim }\end{array}$ & $\begin{array}{l}\text { Hati-hati, mungkin kamu } \\
\text { merasa aman dengan } \\
\text { akun anonimmu. Tidak } \\
\text { ada yang tidak } \\
\text { meninggalkan jejak di } \\
\text { internet. Kamu pasti ga } \\
\text { mau kan punya catatan } \\
\text { criminal di kepolisian? } \\
\text { Tindakan yang kamu } \\
\text { lakukan itu adalah } \\
\text { cyberbulliying, dan sanksi } \\
\text { hukumnya sudah jelas di } \\
\text { UU ITE } \\
\text { Jadi, gunakanlah media } \\
\text { sosialmu dengan baik. }\end{array}$ & $\begin{array}{l}\text { Karakter: Perempuan } \\
\text { Lokasi : Di jalan } \\
\text { Media Sosial : Instagram } \\
\text { Kejadian : Komentar jahat di kolom komentar } \\
\text { seorang selebgram dengan akun anonim } \\
\text { Storytelling: } \\
\text { Seorang warga melihat notifikasi Instagram } \\
\text { berisi selebgram yang menguggah foto. Setelah } \\
\text { melihat, warga tersebut merasa kesal dan } \\
\text { memberi komentar jahat dengan akun } \\
\text { anonimnya. Namun akun anonim tersebut dapat } \\
\text { dilacak dengan alat khusus milik kepolisian yang } \\
\text { akhirnya dapat menemukan pemilik asli akun } \\
\text { tersebut. Akhirnya, warga tersebut ditangkap } \\
\text { dan dipenjara. } \\
\text { Information: } \\
\text { Informasi pada klip ini yaitu penjelasan } \\
\text { mengenai jenis-jenis cyberbulliying dan sanksi } \\
\text { hukum terhadap tindak kejahatan cyberbulliying } \\
\text { yang diatur dalam UU ITE No. } 19 \text { Tahun } 2016 \\
\text { pasal } 45 \text { ayat } 3 . \\
\text { Pisebukan pada voice over untuk memiliki etika } \\
\text { dalam menggunakan media sosial. }\end{array}$ \\
\hline & $\begin{array}{l}\text { Mungkin kamu berasa } \\
\text { berita itu penting untuk } \\
\text { dishare. Tapi, kamu yakin } \\
\text { berita itu benar? }\end{array}$ & $\begin{array}{l}\text { Karakter : Laki-laki } \\
\text { Lokasi : Di jalan } \\
\text { Media Sosial : Whatsapp } \\
\text { Kejadian : Sharing berita hoax }\end{array}$ \\
\hline
\end{tabular}




\begin{tabular}{|c|c|c|}
\hline $\begin{array}{l}\text { Klip } 2 . \\
\text { Penyebaran } \\
\text { Hoax }\end{array}$ & $\begin{array}{l}\text { Gimana kalo ternyata itu } \\
\text { hoax? } \\
\text { Hati-hati, jangan sampai } \\
\text { kamu sudah jadi criminal } \\
\text { di dunia cyber. Kamu } \\
\text { mungkin tidak ada } \\
\text { maksud, tapi kamu sudah } \\
\text { ikut menyebarkan berita } \\
\text { bohong } \\
\text { Karena itu, saring dlu } \\
\text { setiap berita yang kamu } \\
\text { terima, cari sumber } \\
\text { informasi pendukung } \\
\text { lainnya. }\end{array}$ & $\begin{array}{l}\text { Storytelling: } \\
\text { Seorang warna melihat pesan di grup Whatsapp } \\
\text { mengenai informasi kesehatan yang ekstrim. } \\
\text { Pesan tersebut langsung diteruskan ke kontak- } \\
\text { kontak di Whatsapp tanpa membaca habis atau } \\
\text { mencari klarifikasinya. Pesan itu akhirnya viral di } \\
\text { berbagai media sosial. Namun, ternyata berita } \\
\text { itu hoax. Akibatnya, semua akun yang } \\
\text { menyebarkan berita tersebut ditelusuri dan } \\
\text { ditangkap sesuai dengan sanksi UU ITE tentang } \\
\text { hoax. } \\
\text { Information: } \\
\text { Informasi yang diberikan pada klip ini yaitu } \\
\text { sanksi hukum terhadap hoax yang diatur dalam } \\
\text { UU ITE No. } 19 \text { Tahun } 2016 \text { pasal } 45 \mathrm{~A} \text { ayat } 1 . \\
\text { Persuasion: } \\
\text { Klip ini diakhiri dengan ajakan untuk menyaring } \\
\text { setiap berita, mencari data pendukung, baru } \\
\text { kemudian membagikan ke orang lain. }\end{array}$ \\
\hline $\begin{array}{l}\text { Klip } 3 . \\
\text { Sharing Video } \\
\text { Pornografi }\end{array}$ & $\begin{array}{l}\text { Mungkin ini hal yang } \\
\text { sepele buat kamu yang } \\
\text { tidak pernah tertangkap } \\
\text { selama ini. Tapi, jangan } \\
\text { tenang dulu. Jejak } \\
\text { digitalmu tidak akan } \\
\text { hilang. Kamu pasti ga } \\
\text { mau kan reputasi yang } \\
\text { sudah kamu bangun jadi } \\
\text { jatuh karena kesalahan } \\
\text { masa lalu? }\end{array}$ & $\begin{array}{l}\text { Karakter : Laki-laki } \\
\text { Lokasi : Di kantor dan pengadilan } \\
\text { Media Sosial : Whatsapp } \\
\text { Kejadian : Sharing video pornografi } \\
\text { Storytelling: } \\
\text { Tampilan awal yaitu perubahan dari mahasiswa, } \\
\text { lulus pake toga, hingga akhirnya menjadi } \\
\text { direktur sebuah perusahaan. Namun, kebiasaan } \\
\text { nonton dan sharing video porno masih terus } \\
\text { dilakukan. Tindakan ini akhirnya ketahuan dan } \\
\text { pelaku ditangkap dan diadili di pengadilan yang } \\
\text { dihadiri istri dan anak. } \\
\text { Information: } \\
\text { Informasi yang diberikan pada klip ini yaitu UU } \\
\text { ITE No. } 19 \text { Tahun } 2016 \text { pasal } 45 \text { ayat } 1 . \\
\text { Persuasion: } \\
\text { Bentuk persuasi menjadi bagian dari storytelling } \\
\text { dan lebih tegas yaitu bahwa sanksi yang didapat } \\
\text { bukan hanya sanksi hukum namun juga sanksi } \\
\text { moral. Keluarga ikut menanggung malu. }\end{array}$ \\
\hline
\end{tabular}




\begin{tabular}{ll}
\hline & Semua tindakan criminal Motion graphic informasi mengenai tipe-tipe \\
& yang dilakukan di dunia pelanggaran cyber crime \\
maya disebut dengan & \\
Klip 4. & cyber crime. Semua Konten : \\
Penjelasan & aktivitas tindakan cyber Berisi penjelasan cyber crime dan semua \\
Cyber crime & crime kini dipantau oleh tindakan yang termasuk dalam cyber crime. \\
& tim cyber patrol dan Dilanjutkan dengan penjelasan cyber patrol dan \\
& ditindak sesuai UU ITE diakhiri dengan tagline \#JagaJari. \\
& No. 19 Tahun 2016. \\
& Karena itu, jaga jari- \\
& jarimu dengan waspada. \\
& Beretikalah yang baik di \\
media social.
\end{tabular}

Sumber Pribadi

\section{Storyboard}

Storyboard merupakan tahap visualisasi storyline, dibuat dalam bentuk sketsa untuk menunjukkan bagaimana konsep cerita ditampilkan secara visual, baik dari sisi tata letak, pilihan gambar, dan transisi framenya. Melalui storyboard dapat terlihat alur animasi adegan demi adegan dan dapat mengetahui kebutuhan aset visual untuk video. Sketsa storyboard ini menjadi acuan dalam membuat gambar versi digital yang kemudian akan dianimasikan.

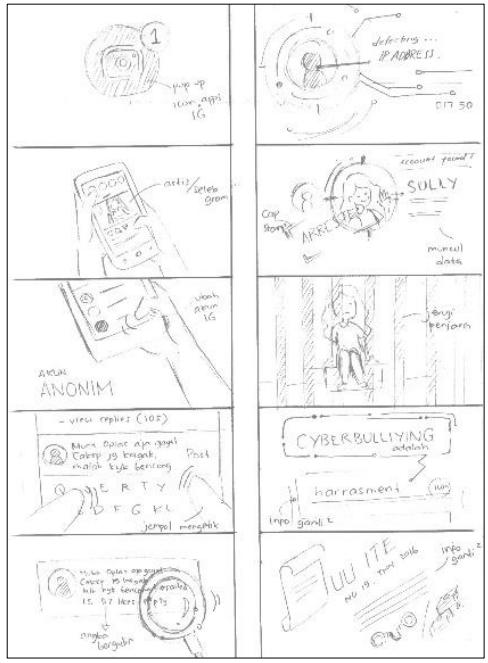

Gambar 3 Sketsa Storyboard
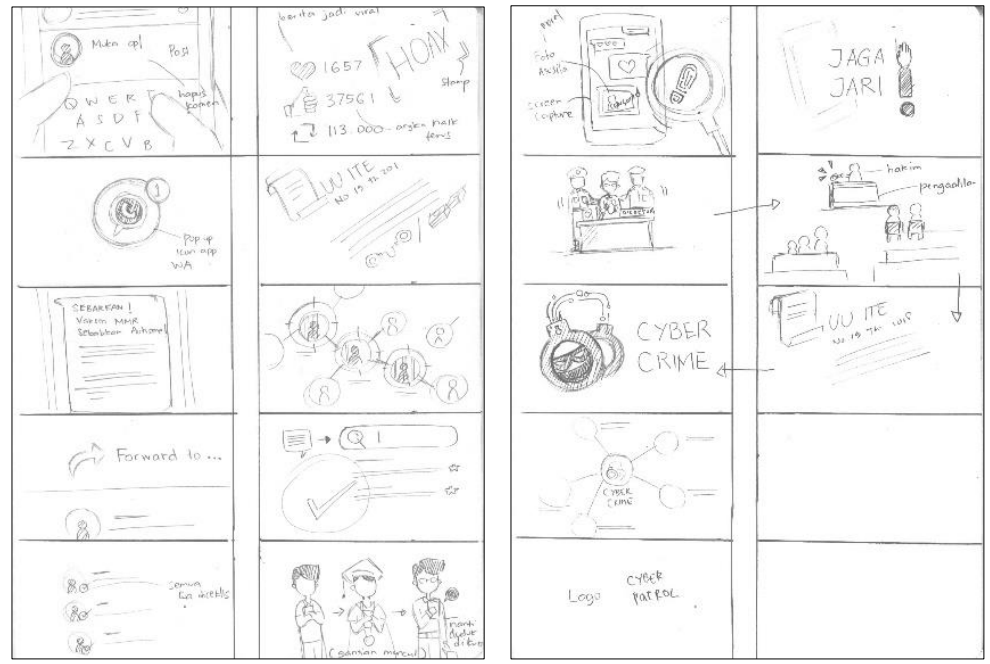

Konsep Visual

Konsep desain video motion graphic ini adalah modern dan minimalis. Konsep ini menyesuaikan target audiens yang merupakan mahasiswa milenial masa kini yang merupakan tech - savvy (sangat memahami teknologi). Konsep desain modern dan minimalis ini dikembangkan menjadi konsep visual sebagai berikut :

\section{Open Composition \& Assymetrical Layout}

Konsep layout ini dipilih untuk menampilkan image dinamis, mobile, dan memunculkan sense of movement, dengan mempertimbangkan target audiens yaitu mahasiswa milenial yang mudah bosan dan suka hal yang dinamis dan cepat. 


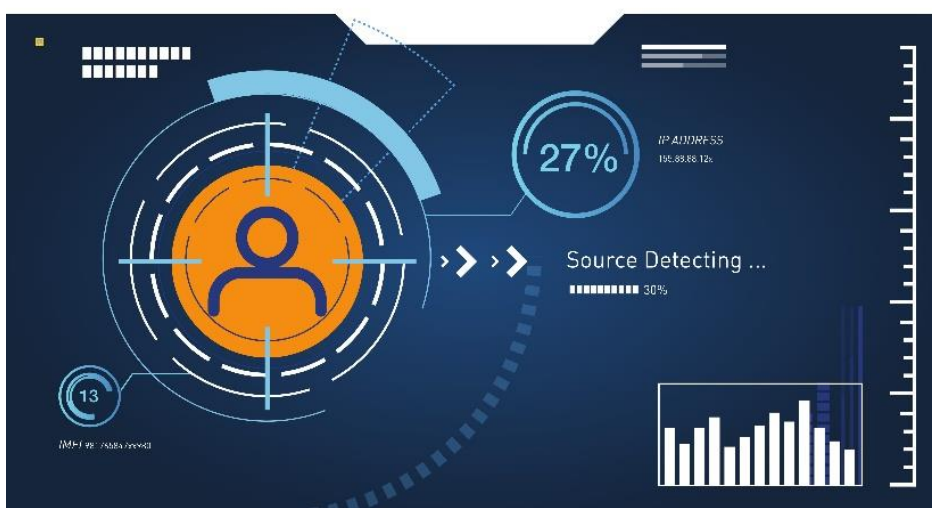

Gambar 4 Open Composition \& Assymetrical Layout

\section{Flat dan Outline Vector Illustration}

Gaya ini dipilih selain untuk menyesuaikan tren 2019 yaitu minimalis, juga agar terlihat ringan dan simple sehingga materi tidak akan terasa berat untuk dipahami oleh mahasiswa. Dari segi visual, pilihan style ini dipilih untuk menampilkan kesan modern. Desain karakter dibuat dengan proporsi tubuh dewasa untuk menunjukkan bahwa target adalah mahasiswa, bukan anak-anak atau remaja.
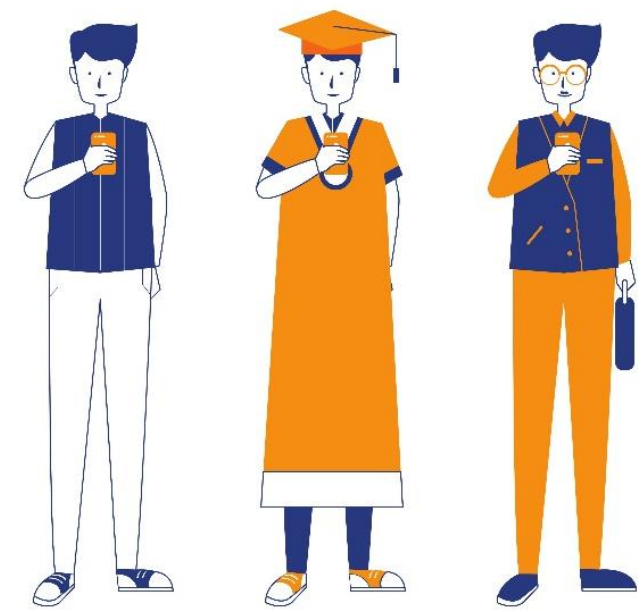

Gambar 5 Flat dan Outline Vector Illustration

\section{Vivid Duo-tone Color}

Pilihan warna vivid dipilih untuk menyesuaikan gaya hidup target yaitu gaul dan senang menjadi pusat perhatian. Duo-tone color dipilih untuk memberi ciri khas pada video motion graphic, juga untuk membantu audiens untuk lebih fokus pada materi. Pilihan warna duo-tone yang digunakan yaitu biru dan orange, karena keduanya merupakan warna komplementer (warna yang bersebrangan dalam lingkaran warna) sehingga dapat menampilkan kombinasi warna yang kontras. 


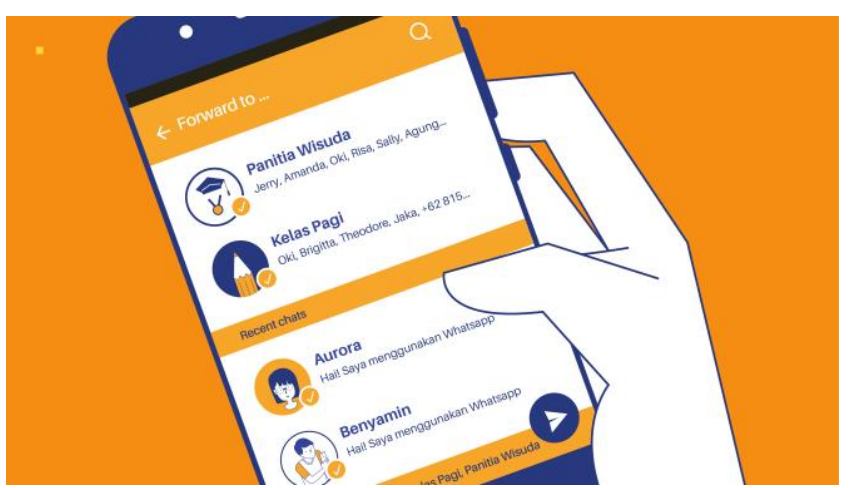

Gambar 6 Vivid Duo-tone Color

\section{Maxi Typography}

Pilihan gaya font ini dipilih untuk memberikan fokus pada kata-kata yang dirasa perlu menjadi perhatian utama.

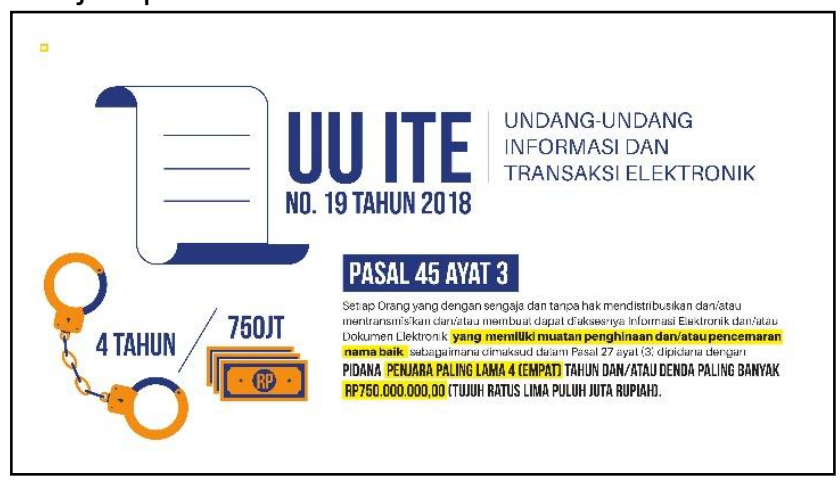

Gambar 7 Maxi Typography

\section{Konsep Komunikasi}

Konsep komunikasi video menyesuaikan gaya komunikasi mahasiswa yang santai, senang menyingkat kata, dan dengan penggunaan istilah-istilah kata yang populer di kalangan mahasiswa. Penyampaian informasi dikemas dalam bentuk storytelling untuk menarik minat mahasiswa dan agar lebih dapat dipahami dengan cara yang sederhana. Pada informasi penting, highlight dan karakter huruf berbeda (bold/italic) digunakan agar poin-poin penting dapat langsung tertangkap mata dan dipahami.

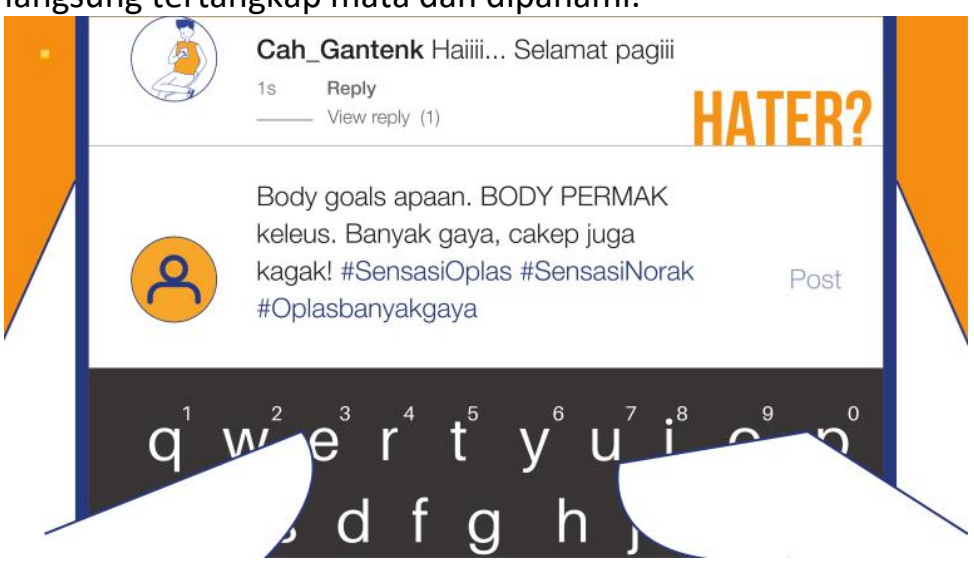

Gambar 8 Penggunaan Fenomena Hashtag dan Istilah Populer/ Gaul 


\section{Tampilan Video Motion graphic}

Video motion graphic "Jaga Jari dari Cyber crime" terbagi menjadi empat klip. Klip pertama sampai dengan ketiga memiliki pola yang serupa yaitu, diawali dengan storytelling, dilanjutkan dengan informasi, dan diakhiri dengan persuasi. Sementara klip terakhir merupakan bagian khusus yang menjelaskan cyber crime.

\section{Klip 1 : Cyberbulliying dengan Akun Anonim}

Instagram adalah media sosial yang dapat digunakan untuk lebih dari satu akun. Pengguna Instagram dengan akun lebih dari satu menggunakan akun keduanya untuk berbagai alasan. Pada kasus ini, keberadaaan akun kedua adalah sebagai akun anonim yang digunakan untuk memberi komentar buruk kepada pengguna akun lain. Anggapan bahwa menggunakan akun anonim untuk cyberbulliying dipatahkan pada clip satu ini, yaitu dengan adanya alat pelacak khusus milik kepolisian yang bisa mendeteksi pemilik akun asli. Pemilihan tokoh perempuan adalah berdasarkan pertimbangan stereotip bahwa perempuan lebih suka bicara daripada laki-laki dan lebih suka bergosip.
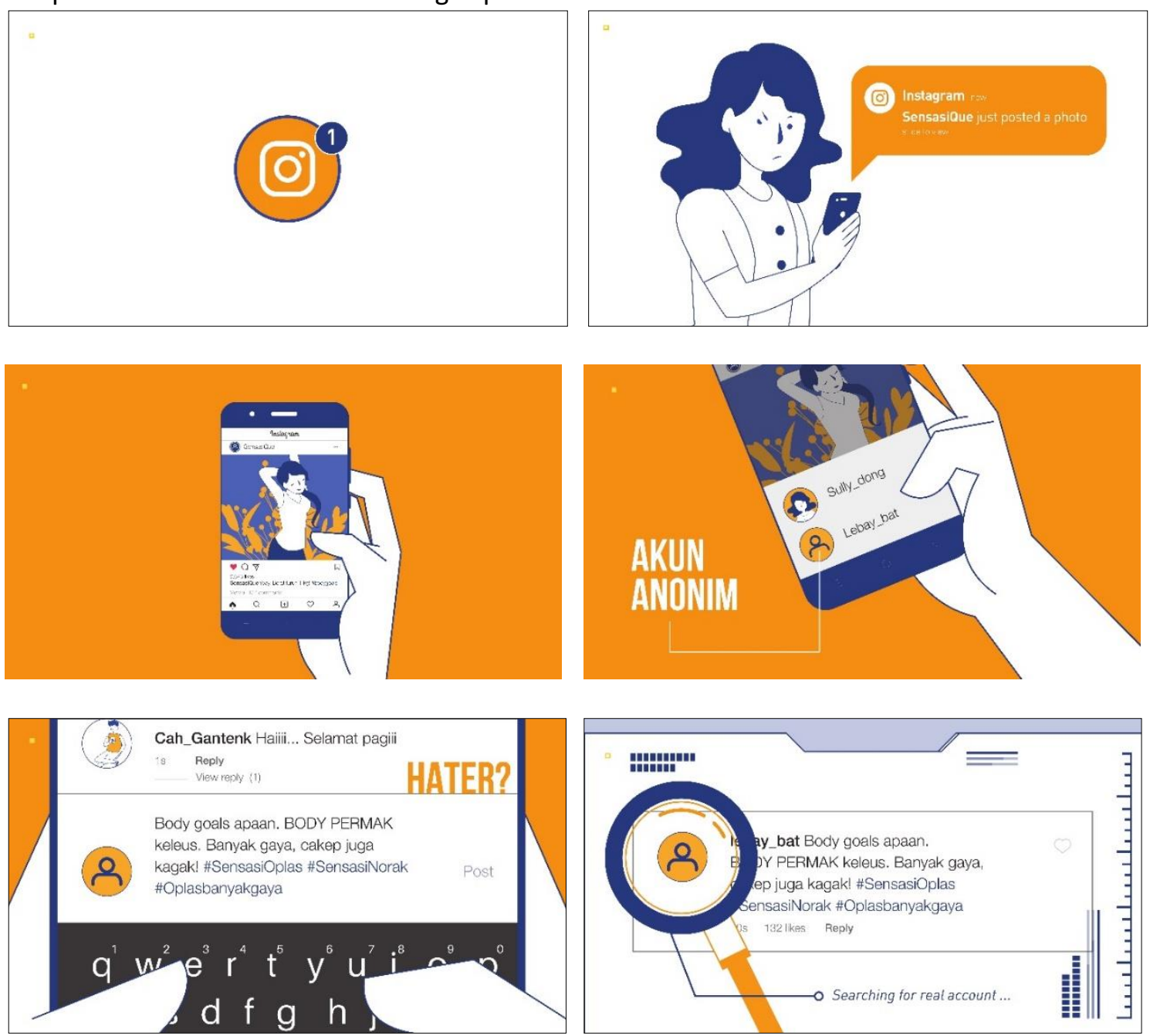

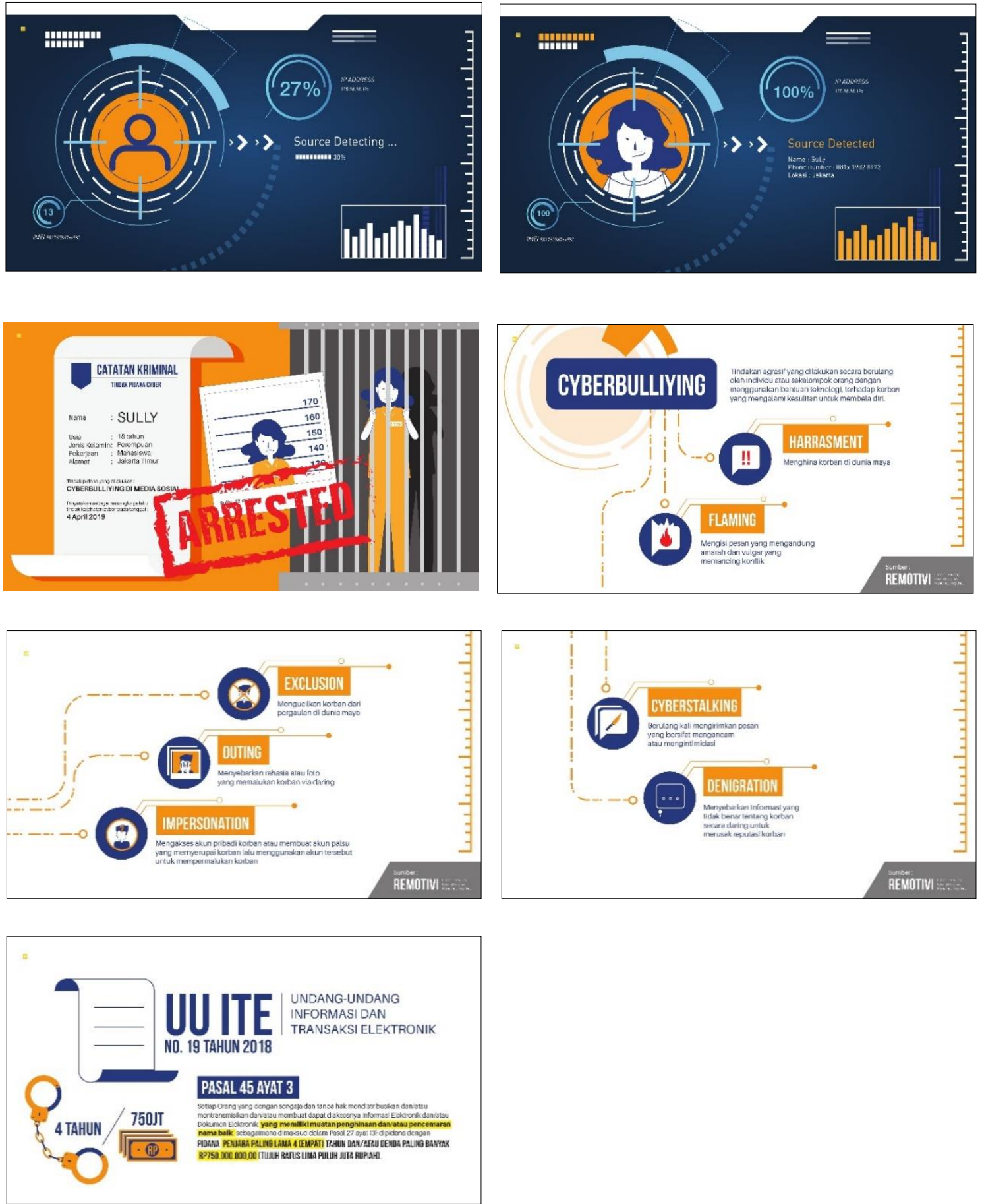

Gamar 9 Tampilan Video Klip 1 : Cyberbulliying

\section{Klip 2 : Penyebaran Hoax}

Whatsapp adalah media sosial yang sering digunakan untuk chatting dengan teman. Fitur grup whatsapp telah banyak digunakan untuk berbagai keperluan, salah satunya adalah kerja kelompok. Pemilihan grup whatsapp kerja kelompok adalah untuk menunjukkan status bahwa pengguna adalah pelajar atau mahasiswa juga agar audiens merasa relate/connect dengan kehidupan mereka. Pemilihan berita kesehatan adalah untuk menunjukkan bahwa kini 
hoax bisa menyerang segala informasi. Pemilihan tokoh laki-laki adalah berdasarkan pertimbangan stereotip bahwa laki-laki kurang teliti dan cenderung lebih malas sehingga pesan seperti itu hanya akan dibaca sekilas dan langsung forward tanpa mengecek kebenaran beritanya.
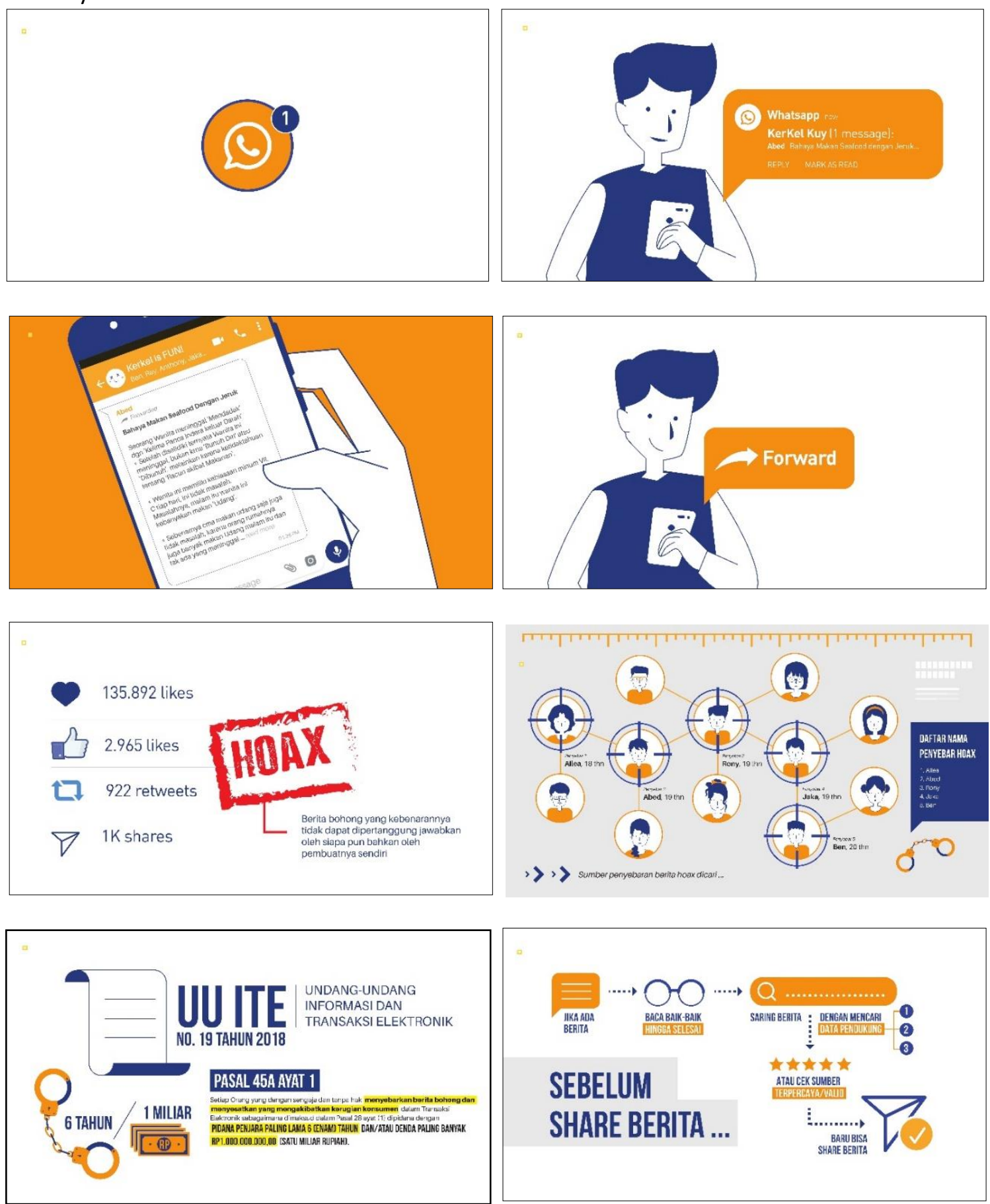

Gambar 10 Tampilan Video Klip 2 : Hoax 


\section{Klip 3 : Penyebaran Pornografi}

Pemilihan jabatan direktur untuk menunjukkan kesuksesan di masa depan, juga sekaligus untuk menunjukkan bahwa kekuasaan tidak akan membantu ketika didapati kesalahan karena tindakan cyber crime. Sharing video pornografi ini masih dianggap biasa oleh sebagian orang, karena itu melalui klip ini, anggapan itu akan dipatahkan karena semua aktivitas cyber crime dapat diketahui dan ada sanksi yang jelas. Pada adegan pengadilan, ada keluarga yang menemani untuk menunjukkan bahwa dampak tindakan kejahatan juga akan menimpa keluarga. Keluarga ikut menanggung malu. Tujuan adegan ini adalah untuk menyentuh sisi moralitas masyarakat terhadap isu pornografi.
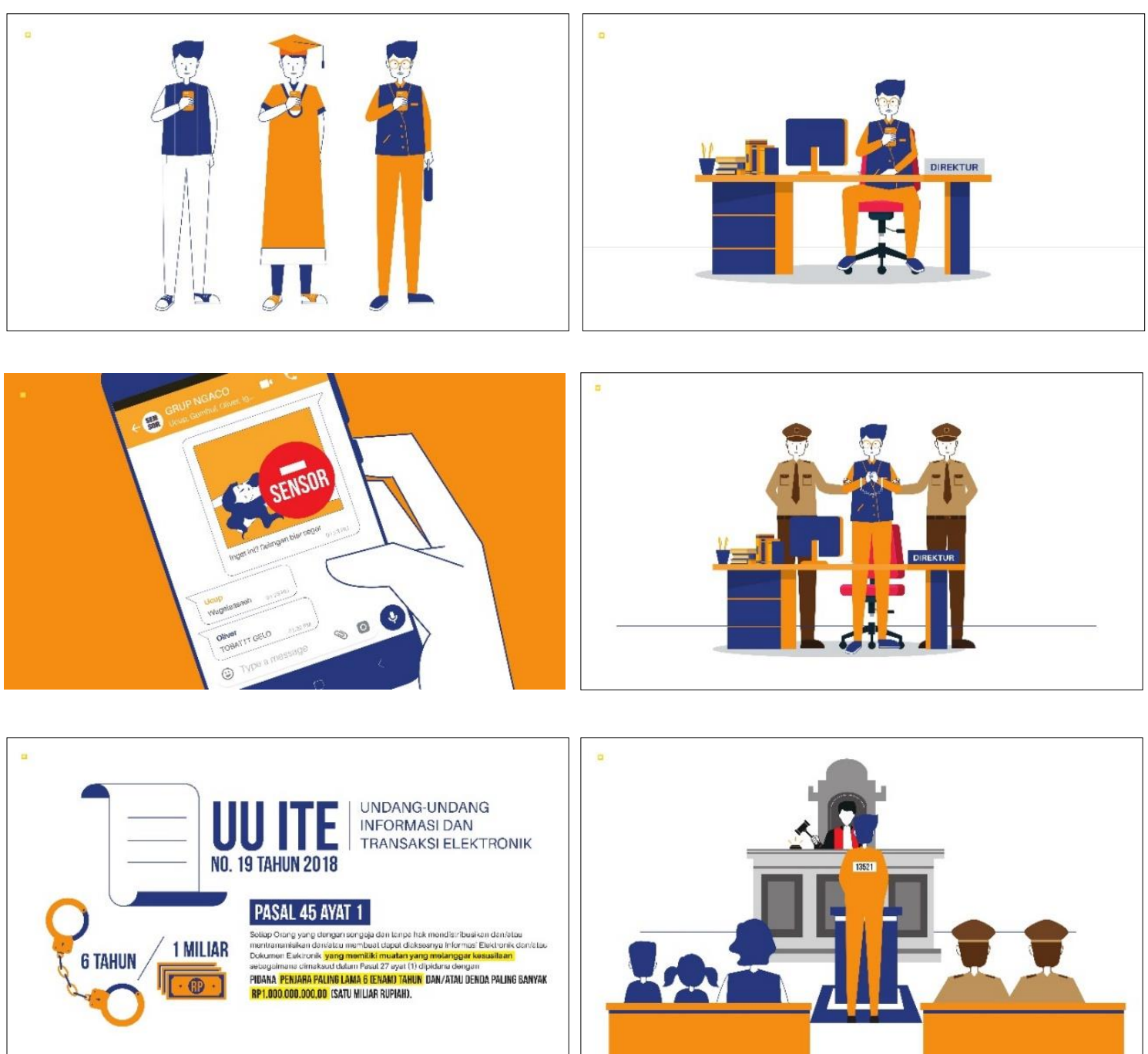

Gambar 11 Tampilan Video Klip 3 : Penyebaran Video Porno

\section{Klip 4 : Penjelasan Cyber crime}

Bagian ini untuk memberikan pengetahuan kepada masyarakat bahwa sesungguhnya ada banyak bentuk kejahatan cyber crime, selain pelanggaran terkait konten. Wawasan ini untuk menyadarkan masyarakat bahwa isu kontemporer cyber crime ini memiliki cakupan yang luas. 

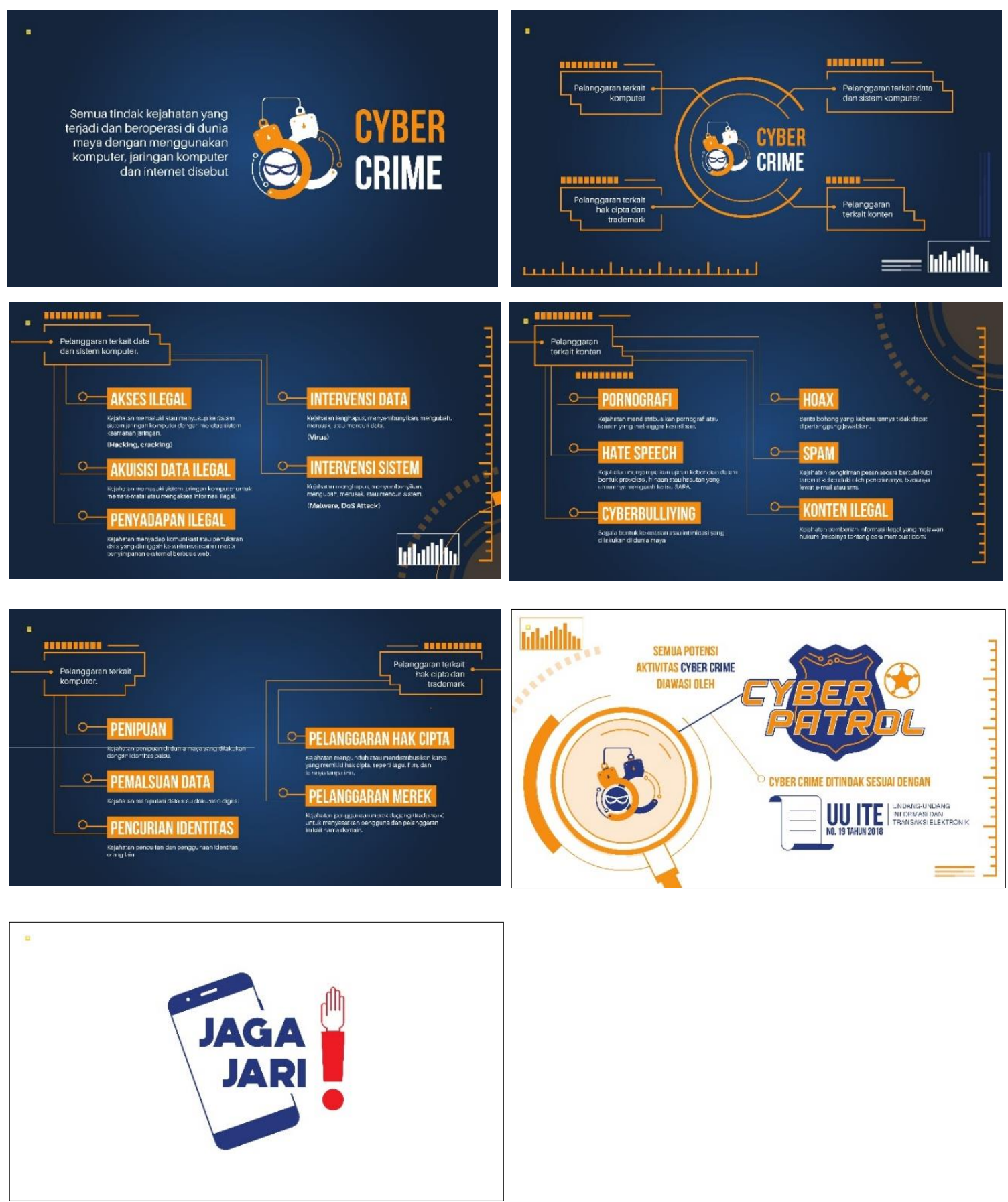

Gambar 12 Tampilan Video Klip 4 : Penjelasan Cyber crime

Musik dan Sound Effect

Background Music yang digunakan adalah musik dengan royalty free dari website www.bensound.com yaitu Sci-Fi yang dibuat Benjamin TISSOT. Beberapa sound effect yang digunakan juga merupakan sound effect dengan royalty free dari website www. freesound.com yaitu Tone beep (by Pan), Missile Lock Detected (by Ryanconway), Chopping Wood (by MAJ061785), Radar 20 Sec (by Mattix), dan Mechanical Keyboard Typing (by stu556). Kredit musik dan efek suara ditampilkan di akhir video. 


\section{Simpulan}

Perancangan video motion graphic merupakan salah satu strategi penyampaian informasi mengenai cyber crime kepada masyarakat, khususnya generasi muda tech-savvy. Kemudahan teknologi, terutama dalam bidang komunikasi, yang diikuti dengan minimnya kesadaran dalam kesiapsiagaan terhadap isu kontemporer cyber crime dapat berakibat pada tindakan kejahatan cyber crime yang terekam dalam jejak digital, dalam kasus ini yaitu jejak digital pada media sosial.

UU ITE No. 19 Tahun 2016 telah mengatur sanksi terhadap tindakan cyber crime. Detil peraturan dan sanksi belum banyak diketahui masyarakat, sehingga mereka tidak sadar akan dampak tindakan cyber crime yang dilakukan. Informasi mengenai cyber crime juga belum banyak disosialisasikan sehingga dapat terjadi kemungkinan masyarakat tidak tahu bahwa tindakan yang dilakukan termasuk tindakan cyber crime. Selain itu, belum banyak masyarakat yang mengetahui bahwa pihak kepolisian memiliki tim Cyber Patrol yang memantau aktivitas cyber crime. Hal ini juga dapat berakibat maraknya tindakan cyber crime karena ada pemikiran bahwa tindakannya tidak akan ketahuan.

Oleh karena itu, video motion graphic mengenai cyber crime ini memuat contoh-contoh kasus cyber crime, penjelasan UU ITE No. 19 Tahun 2016, informasi mengenai cyber patrol, serta himbauan untuk menjaga jari dari cyber crime. Alur informasi pada video ini dikemas menjadi beberapa bagian yaitu :

1. Cerita pendek (short storytelling)

Ada tiga contoh kasus cyber crime, yaitu cyberbulliying, hoax, dan pornografi. Setiap contoh kasus disajikan dalam alur cerita pendek untuk membawa audiens mengikuti cerita seakan sedang menonton film pendek. Durasinya sangkat singkat, yaitu sekitar 1 menit. Cerita pendek ini sebagai pengantar untuk masuk ke dalam penjelasan UU ITE No. 19 Tahun 2016.

2. Informasi tentang UU ITE No. 19 Tahun 2016

Informasi ini berisi mengenai pasal yang mengatur sanksi terhadap tindakan cyber crime, dalam kasus ini yaitu, terkait cyberbulliying, hoax, dan pornografi. Sanksi berupa penjara dan denda dihighlight agar masyarakat menyadari bahwa dampak tindakan cyber crime tidak main-main.

3. Himbauan pencegahan tindakan cyber crime

Pada akhir setiap masing-masing bagian cerita, ditutup dengan himbauan agar masyarakat terhindar dari tindakan cyber crime. Pada akhir video, tagline "Jaga Jari" ditampilkan agar masyarakat untuk berhati-hati menjaga jarinya terutama ketika sedang berkomunikasi di media sosial.

Mahasiswa milenial yang dituju adalah masyarakat yang tidak terlalu senang membaca, suka hal yang instan, dan cepat bosan. Oleh karena itu, strategi komunikasi yang digunakan adalah dengan pendekatan santai, sederhana, dan to-the-point. Penggunaan bahasa pada video menyesuaikan gaya komunikasi mereka yang gaul, asik, dan santai. Tujuannya adalah agar target audiens merasa relate/connect dengan kehidupan mereka.

Strategi visual yang digunakan juga menyesuaikan dengan tujuan video dan karakter target audiens yang modern dan minimalis. Konsep desain ini divisualisasikan dalam open composition dan assymetrical layout, flat dan outline vector illustration, vivid duo-tone color, dan maxi typography. Konsep visual ini juga untuk digunakan untuk membuat konten/pesan terasa lebih segar dan fokus.

Penyebaran video ini dilakukan dengan menggunakan media sosial Youtube, Facebook, Instagram, dan Whatsapp, juga digunakan sebagai materi perkuliahan pada mata kuliah 
Kewarganegaraan. Melalui video ini, informasi mengenai tindakan cyber crime dan dampaknya dapat disosialisasikan kepada masyarakat, tidak ada kelompok masyarakat mahasiswa, namun juga masyarakat luas.

\section{Daftar Pustaka}

Ambrose, Gavin and Paul Harris. Basics Design 08: Design Thinking. 1st (first) Edition edition, Fairchild Books, 2009.

Barrett, Helen. "Researching and Evaluating Digital Storytelling as a Deep Learning Tool." Society for Information Technology \& Teacher Education International Conference, edited by C. Crawford et al., Association for the Advancement of Computing in Education (AACE), Mar 19, 2006 2006, pp. 647-654. https://www.learntechlib.org/p/22117/https://www.learntechlib.org/p/22117/.

Eriviany, Gabriela, et al. Tujuh Wajah Cyberbullying. Remotivi, 2016.

Galaburda, Justas. Icon Design Guide. Icon Utopia, 2016.

Gercke, Marco. Understanding Cybercrime: Phenomena, Challenges and Legal Response ITU publication 2012.

Kusrianto, Adi. Pengantar Desain Komunikasi Visual. CV Andi Offset, 2009.

Robin, Bernard R. "Digital Storytelling: A Powerful Technology Tool for the 21st Century Classroom." Theory into practice, vol. 47, no. 3, 2008, pp. 220-228, doi:https://doi.org/10.1080/00405840802153916.

Supriyono, Rakhmat. "Desain Komunikasi Visual Teori Dan Aplikasi." Yogyakarta: Andi, 2010. 